\title{
Crescimento inicial do milho cultivar brs 1030 sob omissão de nutrientes em solução nutritiva
}

\author{
Ancélio Ricardo de Oliveira Gondim ${ }^{1 *}$, Renato de Mello Prado², Ivana Machado Fonseca ${ }^{3}$, \\ Adriana Ursulino Alves ${ }^{4}$ \\ $10.1590 / 0034-737 X 201663050016$
}

\begin{abstract}
RESUMO
O surgimento de novos híbridos de milho pode afetar a tolerância à deficiência nutricional. Objetivou-se, com este trabalho, caracterizar os sintomas visuais de deficiência de macronutrientes e sua relação com o crescimento, os teores e o acúmulo de nutrientes em milho. O experimento foi realizado em delineamento inteiramente casualizado, com sete tratamentos e três repetições. Os tratamentos consistiram na solução completa de Hoagland \& Arnon (1950), com omissões de N, P, K, Ca, Mg e S. O início dos sintomas de deficiência de N, P, K, Ca e Mg ocorreram aos 5, 16, 16, 16 e 22 dias após o transplantio, respectivamente. O milho apresentou menor produção de matéria seca com a omissão de N, P, $\mathrm{K}$, Ca e Mg, em comparação com o tratamento completo. Os sintomas de deficiência de N, P, K, Ca e Mg foram observados na parte aérea do milho com teores iguais a 7,8;1,2;15,7;1,8 e $0,7 \mathrm{~g} \mathrm{~kg}^{-1}$, respectivamente. No tratamento completo, os teores de N, P, K, Ca e Mg na parte aérea foram de 30,6; 5,9; 63,7; 6,0 e 4,5 g kg-1 sem sintomas de deficiência. A produção de matéria seca diminui quando há a omissão dos nutrientes, tanto para parte aérea como para raízes, e os tratamentos que apresentaram menor produção de matéria seca foram a omissão de $\mathrm{N}$ e a de K. A omissão de um nutriente, além de diminuir seu teor na parte aérea, causa desequilíbrio entre os demais nutrientes e, consequentemente, provoca sintomas característicos de deficiência de cada nutriente.
\end{abstract}

Palavras-chave: Zea mays; cultivo hidropônico; nutrição de plantas.

\section{ABSTRACT}

\section{Initial growthing of corn under nutrient omission in nutritive solution}

The emergence of new corn hybrids may affect tolerance to nutritional deficiency culture. This study aimed to characterize the visual symptoms of macronutrient deficiency and its relation to the development, content and nutrient accumulation in maize. The experiment was arranged in entirely randomized design, with seven treatments and three replications. The plants were cultivated in nutritive complete solution of Hoagland \& Arnon (1950), and the omission of N, P, K, Ca, Mg and S. The onset of symptoms of deficiency of N, P, K, Ca and Mg occurred at 5, 16, 16, 16 and 22, days after the transplant, respectively. The corn had lower dry matter production in the omission of $\mathrm{N}, \mathrm{P}, \mathrm{K}, \mathrm{Ca}$ and $\mathrm{Mg}$ in relation to the complete treatment. Symptoms of deficiency of $\mathrm{N}, \mathrm{P}, \mathrm{K}, \mathrm{Ca}$ and $\mathrm{Mg}$ were observed in the shoots of corn with levels equal to $7.8 ; 1.2 ; 15.7 ; 1.8$ to $0.7 \mathrm{~g} \mathrm{~kg}^{-1}$, respectively. Complete treatment in the $\mathrm{N}, \mathrm{P}, \mathrm{K}, \mathrm{Ca}$ and $\mathrm{Mg}$ in the shoots were $30.6 ; 5.9 ; 63.7 ; 6.0$ and $4.5 \mathrm{~g} \mathrm{~kg}^{-1}$, in that order, good nutritional status. The dry matter production will decrease in the omission of nutrients in the aerial part and in the roots, and the treatments had lower dry matter production were the omission of $\mathrm{N}$ and $\mathrm{K}$. The absence of a nutrient, and reduce its content in the shoot, cause imbalance between the other nutrients, thus providing characteristic symptoms of deficiency of each nutrient.

Key words: Zea mays; hydroponics' cultivate; plant nutrition.

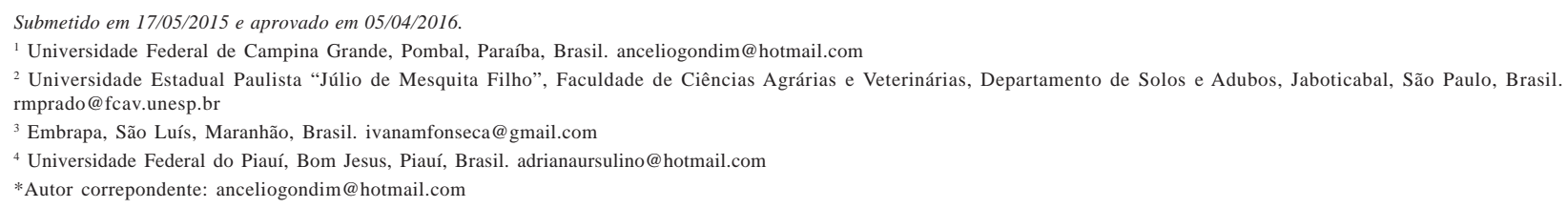




\section{INTRODUÇÃO}

A utilização do milho é muito diversificada e vai desde a alimentação animal até aos subprodutos para alimentação humana. No ano de 2014, a cultura do milho ocupou uma área em torno de 8,6 milhões de hectares, responsável por uma produção de cerca de 42,2 milhões de toneladas de grãos, com rendimento médio de 4.878 $\mathrm{kg} \mathrm{ha}^{-1}$ (IBGE, 2014).

Para a obtenção de produtividades elevadas, o milho necessita ter suas exigências nutricionais plenamente satisfeitas de forma a atender à grande extração de nutrientes, sobretudo de nitrogênio, que é extraído em maior quantidade (Cantarella \& Duarte, 2004), Gondim et al. (2010), trabalhando com a eficiência nutricional do milho na omissão de macronutrientes em solução nutritiva, verificaram que a omissão de macronutrientes promove diminuição da produção de massa seca da parte aérea e da eficiência de absorção de nutrientes. Relatam, ainda, que as omissões de P, $\mathrm{Ca}, \mathrm{Mg}$ e S resultam em maior eficiência de utilização, em comparação com a das plantas nutridas adequadamente.

Nesse contexto, a técnica de cultivo de plantas em solução nutritiva tem permitido avanços no conhecimento da nutrição das plantas e na diagnose foliar, pois controla mais adequadamente a composição da solução e elimina a heterogeneidade e complexidade que se apresentam no solo.

Um dos principais fundamentos da diagnose foliar parte da premissa de que é nas folhas que ocorre a maioria dos processos fisiológicos e metabólicos, devendo seu conteúdo mineral estar sempre relacionado com o desenvolvimento e o aumento da produção. Para atender aos requisitos de produção e de qualidade, os nutrientes devem estar presentes nas folhas, não somente em concentração adequada, mas também dentro de uma relação adequada entre eles (Malavolta et al., 1997). Se o solo ou o adubo não atenderem a esse imperativo, sintomas de carência nutricional e, ou, de toxicidade poderão ocorrer, os quais podem-se manifestar não somente nas folhas, mas, também, nos frutos, raízes, caules e ramos (Malavolta \& Violante Netto, 1989).

Assim, objetivou-se, com este trabalho, caracterizar os sintomas visuais de deficiência de macronutrientes e sua relação com o crescimento inicial, os teores e o acúmulo de nutrientes em plantas de milho cv. BRS 1030.

\section{MATERIAL E MÉTODOS}

O experimento foi realizado em condições de casa de vegetação do Departamento de Solos e Adubos da FCAV/ Unesp, Campus de Jaboticabal, com plantas de milho, cv. BRS 1030. O delineamento estatístico utilizado foi o inteiramente casualizado, com sete tratamentos (soluções nutritivas completas e deficientes em N, P, K, Ca, S, Mg, respectivamente), com três repetições. A unidade experi- mental constituiu-se de um vaso plástico de $2,5 \mathrm{dm}^{3}$, composto por uma planta de milho em solução nutritiva.

Inicialmente, sementes de milho foram colocadas para germinar em tubetes ( $15 \mathrm{~cm}$ de profundidade), preenchidos com substrato composto por casca de pinus compostada, turfa, carvão vegetal e vermiculita, após serem previamente higienizadas em hipoclorito de sódio, a $1 \%$, durante cinco minutos, e lavadas em água destilada. As sementes então foram irrigadas com água até emergência. Logo após, aplicou-se solução nutritiva diluída (25\%) de Hoagland \& Arnon (1950), durante a fase de crescimento inicial, até duas semanas após a emergência.

Após esse período, as plântulas foram selecionadas uniformemente, sendo transplantada uma planta para cada vaso, onde receberam os tratamentos. Após a aplicação dos tratamentos, as plantas de milho foram cultivadas em solução nutritiva durante 30 dias. As soluções nutritivas foram trocadas quinzenalmente e continuamente aeradas, completando-se diariamente o nível da solução no vaso com água deionizada e ajustando-se o valor de $\mathrm{pH}$, entre 5,0 e $6,0, \operatorname{com~} \mathrm{HCl} 0,1 \mathrm{~N}$ ou $\mathrm{NaOH} 1 \mathrm{~N}$.

Semanalmente, efetuaram-se avaliações do crescimento e da sintomatologia (descrição), durante quatro semanas. Avaliaram-se o diâmetro do caule $(2,0 \mathrm{~cm}$ acima do colo), o número de folhas por planta e a altura da planta (do colo da planta até a folha mais alta). No final do experimento, avaliou-se a variável área foliar, com o aparelho eletrônico modelo LI-3100 LICOR ${ }^{\circledR}$.

A sintomatologia causada pelas omissões de nutrientes foi descrita e acompanhada até a completa definição dos sintomas e, após esse período, as plantas foram coletadas, separando-se as partes aérea e de raízes. O material coletado foi lavado em água corrente, posteriormente, enxaguado em água destilada e deionizada, para remoção do excesso de solução nutritiva, acondicionado em sacos de papel e colocado para secagem em estufa com circulação forçada de ar, a $60-65^{\circ} \mathrm{C}$, durante cinco dias. Em seguida, obtendo-se a matéria seca para cada parte da planta, o material foi moído para posterior análise química.

As determinações dos teores de macronutrientes da parte aérea e da raiz foram realizadas conforme método descrito por Bataglia et al. (1983).

Os dados foram submetidos à análise estatística e, se significativos pelo teste $\mathrm{F}(\mathrm{P}<0,05$ e $\mathrm{P}<0,01)$, as médias foram comparadas pelo teste Tukey a 5\% de probabilidade, utilizando-se o programa estatístico SAEG (2007).

\section{RESULTADOS E DISCUSSÃO}

\section{Sintomatologia visual das plantas}

Os inícios de cada fase de aparecimento dos sintomas de deficiências de N, P, K, Ca e Mg ocorreram aos 5, 16, 16, 16 e 22 dias após o transplantio, respectivamente. 
Para o N, primeiramente observou-se que as folhas mais velhas mudaram gradualmente o tom verde-escuro para verde-pálido, ' $\mathrm{V}$ ' invertido, que progrediu para um amarelo uniforme intenso. Houve evolução para clorose generalizada e paralisação do crescimento da parte aérea (Figura 1). Quando o suprimento é subótimo, o crescimento é retardado; o $\mathrm{N}$ que está mobilizado nas folhas adultas é translocado para as mais novas, ocorrendo a senescência das folhas mais velhas (Marschner, 1995). Verificou-se que o sistema radicular apresentou aspecto mais claro do que o considerado normal e, ainda, porte reduzido das plantas, menor área foliar e colmo mais fino, quando comparados com os do tratamento completo.

Marschner (1995) relatou a importância do N não só no crescimento, mas também na divisão celular. Em um experimento com girassol em solução nutritiva, Carelli et al. (1996) observaram que a deficiência de $\mathrm{N}$ provocou diminuição de $31 \%$ na taxa de fotossíntese que, por sua vez, está relacionada com o decréscimo da quantidade da enzima rubisco, visto que parte do $\mathrm{N}$ total da folha está alocada nessa enzima. Assim, quando o teor de N na planta apresenta um valor muito baixo, diversos processos fisiológicos ficam comprometidos, acarretando sintomas visuais de deficiência, conforme descrito anteriormente.

Os sintomas de deficiência de $\mathrm{P}$ foram inicialmente observados por um leve arroxeamento das folhas mais velhas, que se tornou intenso com a evolução da deficiência. As plantas apresentaram porte reduzido, exatamente por esse elemento estar associado à função estrutural e ao processo de transferência e de armazenamento de energia, afetando, com isso, vários processos metabólicos, como a síntese proteica e a de ácidos nucleicos (Mengel \& Kirkby,1987). O surgimento de manchas arroxeadas nas folhas mais velhas foi verificado também por Coelho et al. (2002), em sorgo. A omissão de P também limitou a altura da planta, acarretando porte raquítico, diâmetro e número de folhas menores que os do tratamento completo. Entre as importantes funções exercidas pelo $\mathrm{P}$ na planta, o relevante papel na síntese de proteínas determina que sua carência reflita-se no menor crescimento vegetal (Malavolta, 1980; Marschner, 1995).

A deficiência de $\mathrm{K}$ surgiu inicialmente com pequena clorose acentuada nas margens das folhas velhas, evoluindo para necrose, atingindo os ápices das folhas, as quais,
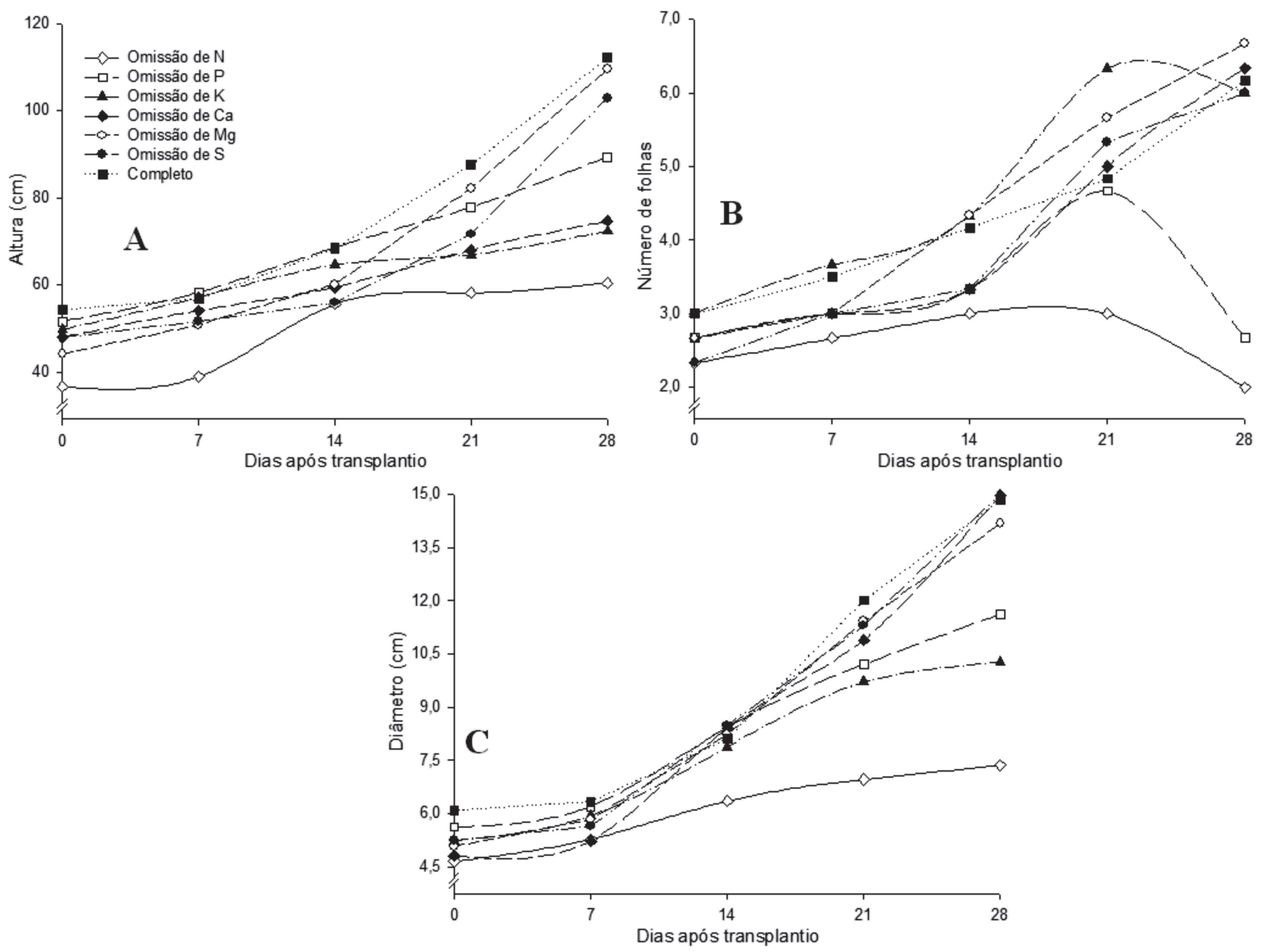

Figura 1: Altura (a), número de folhas (b) e diâmetro de plantas (c) de milho cultivado com omissão de nutrientes, em função de dias após transplantio.

Rev. Ceres, Viçosa, v. 63, n.5, p. 706-714, set/out, 2016 
com a evolução da deficiência, apresentaram grandes manchas necróticas no limbo foliar. Em plantas com deficiência de K, os compostos nitrogenados solúveis, inclusive as aminas e putrescinas, muitas vezes, acumulam-se, sendo a última provavelmente responsável pelas manchas necróticas que aparecem nas folhas deficientes nesse nutriente (Prado, 2008).

A omissão de $\mathrm{Ca}$ acarretou inicialmente anormalidades visíveis nas folhas mais novas, com leve encarquilhamento nas suas margens. Com a evolução da deficiência, ocorreram necrose, morte da gema apical, encarquilhamento total da folha e deformação das folhas novas. Na fase final do experimento, observaram-se necrose do ápice das folhas e dilaceração das margens foliares. As pontas das folhas mais novas grudaram-se umas às outras, à medida que as plantas cresceram, com posteriores murcha e morte das regiões de crescimento. As raízes apresentaram-se pouco desenvolvidas, com encurtamento das raízes secundárias e de coloração castanho-escuro e com ligeiro apodrecimento. $\mathrm{Na}$ literatura, a falta de Ca é caracterizada pela redução do crescimento de tecidos meristemáticos, sendo observado, inicialmente, nas extremidades em crescimento e nas folhas mais jovens (Mengel \& Kirkby, 1987).

O magnésio, ao contrário do que ocorre com o Ca, é móvel no floema; por isso os sintomas manifestam-se primeiro nas folhas mais velhas, como clorose internerval. As folhas inferiores amareleceram da margem para o centro da folha e, depois, entre as nervuras. A nervura principal permaneceu verde. Por terem os sintomas apresentado-se aos 22 DAP (dias após o transplantio), não foi possível atingir o quadro sintomatológico nas folhas novas. As características das deficiências de $\mathrm{Mg}$ descritas para milho coincidem com as apresentadas na maioria das culturas, como por exemplo, as observadas por Santi et al. (2006) e Fonseca et al. (2008) em plantas de sorgo.

\section{Crescimento e Produção de matéria seca}

A deficiência de N, P, K, Ca, Mg e S levaram ao decréscimo de matéria seca da planta inteira. $\mathrm{O}$ tratamento completo apresentou maior acúmulo de matéria seca, em comparação com a dos demais tratamentos com omissão de nutrientes. A omissão de $\mathrm{N}$ foi o mais limitante para a produção inicial de matéria seca da parte aérea e da planta inteira, diferindo significativamente do tratamento completo. Espécies de crescimento inicial rápido, como é o milho, exigem grande quantidade de $\mathrm{N}$ em curto intervalo de tempo, que, se não suprida, resultará em prejuízo ao crescimento inicial dessas espécies (Lima, 1994).

$\mathrm{O}$ tratamento com a omissão de $\mathrm{N}$ apresentou maior limitação do crescimento inicial do milho em todas as avaliações, pois, observou-se que, aos 28 DAP, a planta apresentou altura, diâmetro e número de folhas inferiores aos do tratamento completo. Ao final do experimento, foram obtidas plantas com $60 \mathrm{~cm}$, duas folhas e 7,5 mm, correspondendo, respectivamente, a 52, 33 e 50\% dos valores obtidos com as plantas em solução completa. A restrição de N levou a uma redução de crescimento, pois, conforme Marschner (1995) e Malavolta et al. (1997), esse nutriente, além de fazer parte da estrutura de aminoácidos, proteínas, bases nitrogenadas, ácidos nucleicos, enzimas, coenzimas, vitaminas, pigmentos e produtos secundários, participa de processos como absorção iônica, fotossíntese, respiração, multiplicação e diferenciação celular, os quais interferem direta ou indiretamente no desenvolvimento da planta.

A altura da planta e a área foliar mostraram respostas semelhantes, sendo a omissão de $\mathrm{N}$ a que mais reduziu o crescimento das plantas, seguida das omissões de K, $\mathrm{Ca}, \mathrm{P}, \mathrm{S}$ e $\mathrm{Mg}$, quando comparadas com o das plantas sob cultivo com solução completa (Tabela 1). Além disso, a omissão de $\mathrm{N}$ também apresentou redução da produção de matéria seca, da parte aérea, de $89 \%$, das raízes, de $64 \%$ e, da planta inteira, de $84 \%$, em comparação com as do tratamento completo (Tabela 1). Lima et al. (1981) estudaram o efeito de doses de N (zero; 128 ppm; e 256 ppm) no crescimento de plantas de girassol, cv. Uruguai, cultivadas em solução nutritiva, e observaram que, com o aumento da dose de $\mathrm{N}$, houve acréscimo significativo dos atributos indicativos de crescimento, como a altura, o número de folhas e o peso da matéria seca das diferentes partes da planta. As omissões de N, P, K, Ca, $\mathrm{Mg}$ ou S na solução nutritiva levaram ao decréscimo de matéria seca da parte aérea, das raízes e da planta inteira de plantas de milho, cultivadas sob hidroponia. Portanto, como era esperado, o tratamento sem omissão de nutrientes apresentou maior acúmulo de matéria seca que os demais tratamentos com omissão de nutrientes. A omissão de $\mathrm{N}$ foi o fator mais limitante da produção inicial de matéria seca da parte aérea e da planta inteira, diferindo do tratamento sem omissão de nutrientes. Espécies de crescimento inicial rápido, como o milho, exigem grande quantidade de $\mathrm{N}$ em curto intervalo de tempo e o não suprimento resultará em prejuízo ao crescimento inicial (Almeida et al., 2003).

As plantas de milho foram afetadas pela omissão de $\mathrm{P}$, apresentando reduções da altura da planta, do número de folhas e do diâmetro do caule, em comparação com os do tratamento completo (Figura 1). Houve também redução da produção de matéria seca, da parte aérea, de 74\%; das raízes, de $41 \%$ e da planta inteira, de $68 \%$, em comparação com as do tratamento completo (Tabela 1). Gill et al. (1992) estudaram o efeito da concentração de P (10; 100; e 1000 $\mu \mathrm{M})$ sobre o crescimento de plantas de milho, cv. Gohar, cultivadas em solução nutritiva e observaram que o fósforo foi muito importante para a obtenção de acréscimo significativo do crescimento da planta. 
A planta foi afetada pela omissão de Ca e K, sendo os resultados da altura, número de folhas, diâmetro de caule e matéria seca significativamente inferiores aos das plantas que receberam o tratamento completo (Figura 1).

Os tratamentos com omissão de Ca e K apresentaram índices semelhantes, pois o crescimento em altura foi pouco afetado até 14 dias após o transplantio. Já, na quarta semana (21 dias), esses tratamentos mostraram-se bastante afetados, com alturas inferiores às do tratamento completo. A omissão de Ca não causou diferenças no diâmetro e no número de folhas, em comparação com os do tratamento completo. A omissão de K não causou diferenças no número de folhas, no entanto, o diâmetro foi inferior ao do tratamento completo.

Houve diminuição significativa do número de folhas, do diâmetro de caule e da matéria seca das raízes, das folhas e planta inteira, quando cultivada na solução nutritiva com a omissão de $\mathrm{Mg}$ (Figura 1).

Não houve efeito da omissão de $\mathrm{S}$ sobre o número de folhas, a altura das plantas e o diâmetro do colmo (Figura 1). Assim, essa omissão não teve reflexos na área foliar de milho (Tabela 1), em comparação com a do tratamento completo. Uma justificativa seria que, em condições de estresse (omissão de $\mathrm{S}$ ), as plantas foram capazes de absorver o $\mathrm{SO}_{2}$ atmosférico, embora não seja um processo muito eficiente (Mengel \& Kirkby, 1987).

A diminuição da matéria seca da planta inteira, sob omissão de quaisquer macronutrientes, foi reflexo da redução do número de folhas e da matéria seca da raiz, que influenciaram diretamente os processos fotossintéticos e de absorção de nutrientes.

$\mathrm{O}$ crescimento relativo obedeceu à seguinte ordem decrescente: completo $>-\mathrm{S}=-\mathrm{Mg}>-\mathrm{P}>-\mathrm{Ca}>-\mathrm{K}>-\mathrm{N}$ (Tabela 1). Logo, o desenvolvimento da planta durante o período experimental foi menos afetado pela omissão do $\mathrm{S}$, com redução de $57 \%$ da matéria seca, e mais afetada pelo N, com redução de $85 \%$ da matéria seca, em comparação com a do tratamento completo. Santi et al. (2006), estudando o efeito da omissão de nutrientes em sorgo, encontraram decréscimo de produção de matéria seca: $-\mathrm{S}$ $>-\mathrm{K}>-\mathrm{P}>-\mathrm{Mg}>-\mathrm{N}>-\mathrm{Ca}$.

A relação parte aérea (PA)/raiz (R) do milho foi afetada pela deficiência dos nutrientes. Os tratamentos com omissão de $\mathrm{Mg}$, S e K apresentaram alta relação PA/R, indicando maior biomassa da parte aérea, em comparação com a matéria seca da raiz (Tabela 1). Este efeito da deficiência de $\mathrm{Mg}$ e de $\mathrm{K}$ em proporcionar maior acúmulo de matéria seca da parte aérea, em detrimento da matéria seca da raiz, também foi relatado por Ericson (1995). As menores relações PA/R foram observadas para os tratamentos desprovidos de $\mathrm{N}$ e de $\mathrm{P}$, por causa da maior partição de carboidratos destinados à produção de raízes, que ocorre quando uma planta apresenta deficiência desses nutrientes (Marschner, 1995). Quando o N está em deficiência, a concentração na parte aérea será mais baixa do que a da raiz, porque a parte aérea é uma fonte adicional de N. Isso ocorre porque a maior parte de $\mathrm{N}$ presente na parte aérea é proveniente do transporte de $\mathrm{N}$ por via do xilema pelas raízes, retornando para as raízes pelo floema (Cooper \& Clarkson, 1989). Ericson (1995) relata que o decréscimo da relação PA/R é comum em plantas crescidas com deficiência de $\mathrm{P}$.

\section{Teor e Acúmulo de Nutrientes}

Os teores de $\mathrm{N}$ da parte aérea e das raízes variaram de 30,1 a 45,2 e 16,8 a 44,8 $\mathrm{g} \mathrm{kg}^{-1}$, respectivamente, em todos os tratamentos, exceto no tratamento com omissão de $\mathrm{N}$ (Tabela 2). Esses teores de $\mathrm{N}$ da parte aérea estão dentro da faixa, considerada adequada para a cultura, de 27,5 a $32,5 \mathrm{~g} \mathrm{~kg}^{-1}$ (Martinez et al. 1999). Verificou-se que a omissão de $\mathrm{N}$ ocasionou redução do teor desse nutriente em todas as partes da planta, quando comparado com o do tratamento completo (Tabela 2). O mesmo foi observado por Viégas et al. (2002).

$\mathrm{O}$ tratamento completo apresentou teor de $\mathrm{N}$ da parte aérea de $30,6 \mathrm{~g} \mathrm{~kg}^{-1}$, enquanto, no tratamento com omis-

Tabela 1: Produção de matéria seca da parte aérea, das raízes e da planta inteira de milho cultivado com omissão de nutrientes, crescimento relativo (CR), relação parte aérea/raiz (PA/R) e área foliar (AF) das plantas

\begin{tabular}{|c|c|c|c|c|c|c|}
\hline \multirow{3}{*}{ Tratamento } & \multicolumn{3}{|c|}{ Matéria seca } & \multirow{3}{*}{$\begin{array}{c}\text { CR } \\
\%\end{array}$} & \multirow{3}{*}{$\mathbf{P A} / \mathbf{R}$} & \multirow{3}{*}{$\frac{\mathrm{AF}}{\mathrm{cm}^{2}}$} \\
\hline & Parte aérea & Raiz & Planta inteira & & & \\
\hline & \multicolumn{3}{|c|}{ g por planta } & & & \\
\hline Completo & $15,60 \mathrm{a}$ & $3,14 \mathrm{a}$ & $18,74 a$ & 100 & 4,97 & $1766,36 a$ \\
\hline$-\mathrm{N}$ & $1,76 \mathrm{c}$ & $1,13 \mathrm{bc}$ & $2,89 \mathrm{c}$ & 15,42 & 1,56 & $285,13 d$ \\
\hline$-\mathrm{P}$ & $4,04 \mathrm{bc}$ & $1,85 b$ & $5,89 \mathrm{bc}$ & 31,43 & 2,18 & $832,78 \mathrm{bcd}$ \\
\hline$-\mathrm{K}$ & $3,04 \mathrm{bc}$ & $0,72 \mathrm{c}$ & $3,76 \mathrm{bc}$ & 20,06 & 4,22 & $652,71 \mathrm{~cd}$ \\
\hline$-\mathrm{Ca}$ & $4,05 \mathrm{bc}$ & $1,20 b c$ & $5,25 \mathrm{bc}$ & 28,01 & 3,37 & $795,00 \mathrm{bcd}$ \\
\hline$-\mathrm{Mg}$ & $6,91 b$ & $1,08 \mathrm{bc}$ & $7,99 \mathrm{bc}$ & 42,64 & 6,40 & $1606,30 \mathrm{ab}$ \\
\hline$-S$ & $6,60 \mathrm{~b}$ & $1,41 b c$ & $8,01 \mathrm{~b}$ & 42,74 & 4,68 & $1337,24 \mathrm{abc}$ \\
\hline$\overline{\mathrm{CV}(\%)}$ & 24,3 & 25,6 & 24,4 & - & - & 28,0 \\
\hline
\end{tabular}

Rev. Ceres, Viçosa, v. 63, n.5, p. 706-714, set/out, 2016 
são desse nutriente, o teor foi de $7,8 \mathrm{~g} \mathrm{~kg}^{-1}$. Entretanto, nas raízes, observou-se que as plantas submetidas à omissão de $\mathrm{N}$ apresentaram menor teor do nutriente, de 6,8 $\mathrm{g}$ $\mathrm{kg}^{-1}$, se comparado ao do tratamento completo, de $23,9 \mathrm{~g}$ $\mathrm{kg}^{-1}$ (Tabela 2). O mesmo ocorreu com os teores de $\mathrm{N}$ acumulados pela parte aérea e pelas raízes, maiores no tratamento completo, de 57,3 mg por planta, comparados aos deficientes $(2,2$ e 2,0 $\mathrm{mg})$ por planta, respectivamente (Tabela 3).

Na planta inteira, o milho acumulou $102,1 \mathrm{mg}$ de $\mathrm{N}$ por planta, com o tratamento completo, sendo que a parte aérea foi responsável por $56 \%$ e, a raiz, por $44 \%$ do acumulado. O acúmulo na parte aérea foi de $57,3 \mathrm{~g}$ por planta, aos 30 dias após o transplantio.

Os teores de $\mathrm{P}$ da parte aérea e da raiz variaram de 5,9 a 9,9 e de 4,5 a 10,8 $\mathrm{g} \mathrm{kg}^{-1}$, respectivamente, em todos os tratamentos, exceto no tratamento com omissão de $\mathrm{P}$ (Tabela 2). $\mathrm{O}$ menor valor de $1,2 \mathrm{~g} \mathrm{~kg}^{-1}$ foi observado com o tratamento com omissão de $\mathrm{P}$, que foi considerado inadequado para plantas de milho, por estar abaixo da faixa considerada adequada para a cultura, de 2,5 a $3,5 \mathrm{~g} \mathrm{~kg}^{-1}$ (Martinez et al. 1999). Hernandez \& Silveira (1998), estudando os efeitos da saturação por bases, relações Ca:Mg em vaso e níveis de fósforo, verificaram, para a relação Ca:Mg e saturação por base de $70 \%$, um teor de fósforo de $3,1 \mathrm{~g} \mathrm{~kg}^{-1}$ na parte aérea das plantas de milho. Mesmo estando a planta em condições de deficiência, ela pode usar a quantidade mínima de nutrientes existente nos órgãos e utilizá-la com maior eficiência, em comparação com as plantas adequadamente nutridas, conforme relataram Gondim et al. (2010).
As plantas que receberam o tratamento com omissão de fósforo apresentaram redução significativa do teor do nutriente da parte aérea, em relação ao tratamento completo, respectivamente, de 5,9 para 1,2, e, das raízes, de 4,5 para $0,7 \mathrm{~g} \mathrm{~kg}^{-1}$ (Tabela 2). Acrescente-se, ainda, que houve diminuição do $\mathrm{P}$ acumulado na parte aérea, de 11,1 para $0,7 \mathrm{mg}$ por planta e, nas raízes, de 8,4 para $0,4 \mathrm{mg}$ por planta (Tabela 3). Observou-se que a omissão de fósforo causou menor absorção dos outros nutrientes (Tabela 3).

Os teores de $\mathrm{K}$ da parte aérea e das raízes variaram de 49,0 a 83,3 e de 30,8 a $39,4 \mathrm{~g} \mathrm{~kg}^{-1}$, respectivamente, em todos os tratamentos, exceto no tratamento com omissão de $\mathrm{K}$ (Tabela 2). O menor valor de $13,6 \mathrm{~g} \mathrm{~kg}^{-1}$ foi observado em plantas sob o tratamento com omissão de $\mathrm{K}$, que foi considerado inadequado para plantas de milho, por estar abaixo da faixa, considerada adequada para a cultura, de 17,5 a 22,5 $\mathrm{g} \mathrm{kg}^{-1}$ (Martinez et al., 1999). Os maiores teores de $\mathrm{K}$ na parte aérea e nas raízes ocorreram com a omissão de P, de Mg e de S. Santi et al. (2006) também observaram em sorgo maior teor de $\mathrm{K}$ nas raízes com a omissão de Mg. As plantas submetidas à omissão de $\mathrm{K}$ apresentaram menor teor do nutriente da parte aérea, de $15,7 \mathrm{~g} \mathrm{~kg}^{-1}$, e das raízes, de $6,0 \mathrm{~g} \mathrm{~kg}^{-1}$, quando comparadas com o do tratamento completo, na parte aérea de $63,7 \mathrm{~g}$ $\mathrm{kg}^{-1}$ e também nas raízes, de $30,8 \mathrm{~g} \mathrm{~kg}^{-1}$ (Tabela 2). O mesmo ocorreu com o $\mathrm{K}$ acumulado pelas plantas, tendo maior acúmulo do nutriente no tratamento completo (parte aérea, de 119,2, e raízes, de 57,6 mg por planta), se comparado com os dos tratamentos deficientes, (parte aérea, de 5,7 e, raízes, de 2,3 mg por planta) (Tabela 3). Essa menor absorção do K no tratamento com omissão do elemento

Tabela 2: Teores $\left(\mathrm{g} \mathrm{kg}^{-1}\right)$ dos macronutrientes na parte aérea e nas raízes das plantas de milho cultivadas com omissão de nutrientes

\begin{tabular}{|c|c|c|c|c|c|c|}
\hline \multirow{2}{*}{ Tratamentos } & $\mathbf{N}$ & $\mathbf{P}$ & $\mathbf{K}$ & $\mathrm{Ca}$ & Mg & $\mathbf{S}$ \\
\hline & \multicolumn{5}{|c|}{ Parte aérea } & \\
\hline Completo & $30,60 \mathrm{~b}$ & $5,93 b$ & $63,67 \mathrm{ab}$ & $6,03 b$ & $4,53 b$ & $1,80 \mathrm{bc}$ \\
\hline$-\mathrm{N}$ & $7,83 \mathrm{c}$ & $8,13 \mathrm{ab}$ & $49,77 b$ & $7,50 \mathrm{~b}$ & $3,27 \mathrm{~b}$ & $0,93 \mathrm{c}$ \\
\hline$-\mathrm{P}$ & $30,10 \mathrm{~b}$ & $1,20 \mathrm{c}$ & $83,33 a$ & $7,23 b$ & $3,67 \mathrm{~b}$ & $1,67 b c$ \\
\hline$-\mathrm{K}$ & $43,30 \mathrm{a}$ & $9,93 \mathrm{a}$ & $15,73 \mathrm{c}$ & $11,97 \mathrm{a}$ & $7,10 \mathrm{a}$ & $2,80 \mathrm{ab}$ \\
\hline$-\mathrm{Ca}$ & $45,17 \mathrm{a}$ & $8,73 a$ & $48,97 b$ & $1,80 \mathrm{c}$ & $7,23 \mathrm{a}$ & $3,67 \mathrm{a}$ \\
\hline$-\mathrm{Mg}$ & $32,20 \mathrm{~b}$ & $8,60 \mathrm{a}$ & $71,33 \mathrm{ab}$ & $6,17 \mathrm{~b}$ & $0,73 \mathrm{c}$ & $1,53 \mathrm{bc}$ \\
\hline$-S$ & $33,03 b$ & $5,93 \mathrm{~b}$ & $79,33 \mathrm{a}$ & $7,57 \mathrm{~b}$ & $3,53 \mathrm{~b}$ & $1,47 \mathrm{c}$ \\
\hline \multirow[t]{2}{*}{ CV (\%) } & 5,7 & 12,1 & 13,9 & 15,0 & 15,5 & 23,7 \\
\hline & \multicolumn{5}{|c|}{ Raiz } & \\
\hline Completo & $23,93 b$ & $4,50 \mathrm{bc}$ & $30,83 a$ & $7,07 \mathrm{abc}$ & $7,07 \mathrm{a}$ & $6,80 \mathrm{ab}$ \\
\hline$-\mathrm{N}$ & $6,80 \mathrm{~d}$ & $10,80 \mathrm{a}$ & $31,73 \mathrm{a}$ & $1,37 \mathrm{c}$ & $1,33 \mathrm{de}$ & $3,20 \mathrm{c}$ \\
\hline$-\mathrm{P}$ & $16,80 \mathrm{c}$ & $0,67 \mathrm{c}$ & $33,13 a$ & $2,63 b c$ & $1,50 \mathrm{de}$ & $4,13 b c$ \\
\hline$-\mathrm{K}$ & $40,50 \mathrm{a}$ & $9,37 \mathrm{ab}$ & $6,03 b$ & $13,20 \mathrm{a}$ & $2,30 \mathrm{~cd}$ & $5,00 \mathrm{abc}$ \\
\hline$-\mathrm{Ca}$ & $44,80 \mathrm{a}$ & $9,20 \mathrm{ab}$ & $32,17 \mathrm{a}$ & $1,23 \mathrm{c}$ & $3,20 \mathrm{c}$ & $7,20 \mathrm{a}$ \\
\hline - Mg & $26,52 b$ & $8,33 \mathrm{ab}$ & $38,20 \mathrm{a}$ & $9,87 \mathrm{ab}$ & $0,90 \mathrm{e}$ & $4,33 b c$ \\
\hline$-S$ & $23,37 \mathrm{bc}$ & $9,53 \mathrm{ab}$ & $39,40 \mathrm{a}$ & $7,20 \mathrm{abc}$ & $4,90 \mathrm{~b}$ & $2,27 \mathrm{c}$ \\
\hline$\overline{\mathrm{CV}(\%)}$ & 9,1 & 25,7 & 12,2 & 48,8 & 15,9 & 21,1 \\
\hline
\end{tabular}


ocasionou o aparecimento de sintomas visuais, como descritos anteriormente.

O nitrogênio e o potássio foram os nutrientes mais acumulados na fase inicial de desenvolvimento do milho. É conhecida a importância do nitrogênio como constituinte essencial dos aminoácidos, principais integrantes de proteínas, além da sua atuação na divisão celular e na produção de clorofila. Por sua vez, o potássio atua em processos osmóticos, na síntese de proteínas, na manutenção da estabilidade e da permeabilidade das membranas e no controle do pH (Malavolta et al., 1997; Marschner, 1995). Essas funções de ambos os nutrientes podem explicar a exigência da planta, que se encontra em intensa atividade metabólica nessa fase inicial de desenvolvimento.

Os teores de Ca da parte aérea e das raízes variaram de 6,2 a 12,0 e de 1,4 a 13,2 $\mathrm{g} \mathrm{kg}^{-1}$, respectivamente, em todos os tratamentos, exceto no tratamento com omissão de $\mathrm{Ca}$ (Tabela 2). Esses teores da parte aérea estão acima da faixa, considerada adequada para a cultura, de 2,5 a 4,0 g $\mathrm{kg}^{-1}$ (Martinez et al. 1999).

Observou-se maior teor de $\mathrm{Ca}$, tanto da parte aérea como das raízes, na ausência de K. Santi et al. (2006), estudando os efeitos de omissão de nutrientes em sorgo, encontraram os mesmos resultados. Por outro lado, a redução dos teores de Ca das raízes foi observada com as omissões de $\mathrm{N}$ e de $\mathrm{P}$, fatos também observados por Santi et al. (2006). Evidenciou-se que a omissão de Ca ocasionou menores teores em todas as partes da planta (Tabela 2). Além disso, nos tratamentos com ausência de N, P, e S, os teores de Ca das raízes não diferiram daqueles dos tratamento com omissão desse nutriente.

As plantas submetidas à omissão de Ca apresentaram menores teores do nutriente na parte aérea, de $1,8 \mathrm{~g} \mathrm{~kg}^{-1}$, e nas raízes de $1,2 \mathrm{~g} \mathrm{~kg}^{-1}$, comparado ao tratamento completo na parte aérea de $6,0 \mathrm{~g} \mathrm{~kg}^{-1}$ e nas raízes de $7,1 \mathrm{~g} \mathrm{~kg}^{-1}$ (Tabela 2). O mesmo ocorreu com o Ca acumulado pelas plantas, tendo maior acúmulo do nutriente no tratamento completo, na parte aérea de 11,3 e nas raízes, de 13,3 mg por planta, quando comparado com os teores dos tratamentos deficientes, sendo encontrados, na parte aérea, 0,9 e, nas raízes, $0,7 \mathrm{mg}$ por planta (Tabela 3 ).

Os teores de $\mathrm{Mg}$ das partes aérea e raízes variaram de 3,3 a 7,3 e de 1,3 a 7,1 $\mathrm{g} \mathrm{kg}^{-1}$, respectivamente, em todos os tratamentos, exceto no tratamento com omissão de $\mathrm{Mg}$ (Tabela 2). O menor valor de $0,8 \mathrm{~g} \mathrm{~kg}^{-1}$ foi observado em plantas sob o tratamento com omissão de $\mathrm{Mg}$, considerado inadequado para plantas de milho, por estar abaixo da faixa considerada adequada para a cultura, de 2,5 a 4,0 $\mathrm{g}$ $\mathrm{kg}^{-1}$ (Martinez et al. 1999). O teor de $\mathrm{Mg}$ da parte aérea foi de $4,5 \mathrm{~g} \mathrm{~kg}^{-1}$, no tratamento completo, e de $0,7 \mathrm{~g} \mathrm{~kg}^{-1}$, na parte aérea, sob o tratamento com omissão de $\mathrm{Mg}$ (Tabela 1).

Verificou-se redução do teor de $\mathrm{Mg}$ de todas as partes das plantas, quando omitido da solução nutritiva (Tabela 2). Resultados semelhantes foram encontrados por Santi $e t$ al. (2006). As omissões de $\mathrm{N}$ e de $\mathrm{P}$, em relação à raiz, não diferiram do tratamento com ausência de Mg. Também, na presença do tratamento com a omissão de potássio, observou-se um aumento do teor de $\mathrm{Mg}$ da parte aérea, em rela-

Tabela 3: Acúmulo de macronutrientes (mg por planta) na parte aérea e nas raízes das plantas de milho cultivadas com omissão de nutrientes

\begin{tabular}{|c|c|c|c|c|c|c|}
\hline Tratamentos & $\mathbf{N}$ & $\mathbf{P}$ & $\mathbf{K}$ & $\mathbf{C a}$ & Mg & $\mathbf{S}$ \\
\hline \multicolumn{7}{|c|}{ Parte aérea } \\
\hline Completo & $57,3 \mathrm{a}$ & $11,1 \mathrm{a}$ & $119,2 \mathrm{a}$ & $11,3 \mathrm{a}$ & $8,5 \mathrm{a}$ & $3,4 \mathrm{a}$ \\
\hline$-\mathrm{N}$ & $2,2 \mathrm{c}$ & $2,3 \mathrm{~cd}$ & $14,6 \mathrm{~d}$ & $2,1 \mathrm{~cd}$ & $0,9 \mathrm{c}$ & $0,3 c$ \\
\hline$-\mathrm{P}$ & $17,7 \mathrm{bc}$ & $0,7 \mathrm{~d}$ & $48,9 \mathrm{bc}$ & $4,2 \mathrm{bc}$ & $2,1 b c$ & $1,0 \mathrm{bc}$ \\
\hline$-\mathrm{K}$ & $16,1 b c$ & $3,9 \mathrm{bcd}$ & $5,7 \mathrm{~d}$ & $4,4 b c$ & $2,7 b c$ & $1,0 \mathrm{bc}$ \\
\hline$-\mathrm{Ca}$ & $23,7 b$ & $4,6 \mathrm{bcd}$ & $24,6 \mathrm{~cd}$ & $0,9 \mathrm{~d}$ & $3,5 b$ & $1,8 \mathrm{~b}$ \\
\hline$-\mathrm{Mg}$ & $25,70 \mathrm{~b}$ & $6,8 \mathrm{abc}$ & $57,1 \mathrm{~b}$ & $4,9 b$ & $0,6 \mathrm{c}$ & $1,2 \mathrm{bc}$ \\
\hline$-S$ & $26,7 b$ & $7,2 \mathrm{ab}$ & $63,8 b$ & $5,8 b$ & $2,8 b c$ & $1,1 b c$ \\
\hline$\overline{\mathrm{CV}(\%)}$ & 30,8 & 32,0 & 21,0 & 18,2 & 30,7 & 31,9 \\
\hline \multicolumn{7}{|c|}{ Raízes } \\
\hline Completo & $44,8 \mathrm{a}$ & $8,4 a$ & $57,6 \mathrm{a}$ & $13,3 \mathrm{a}$ & $13,2 \mathrm{a}$ & $12,7 \mathrm{a}$ \\
\hline$-\mathrm{N}$ & $2,0 \mathrm{c}$ & $3,1 \mathrm{bc}$ & $9,1 \mathrm{c}$ & $0,4 \mathrm{e}$ & $0,4 \mathrm{c}$ & $0,9 b$ \\
\hline$-\mathrm{P}$ & $1,0 \mathrm{bc}$ & $0,4 \mathrm{c}$ & $19,4 \mathrm{bc}$ & $1,5 \mathrm{de}$ & $0,9 \mathrm{c}$ & $2,4 b$ \\
\hline$-\mathrm{K}$ & $15,0 \mathrm{bc}$ & $3,1 \mathrm{bc}$ & $2,3 c$ & $4,2 \mathrm{~cd}$ & $0,9 \mathrm{c}$ & $1,9 \mathrm{~b}$ \\
\hline$-\mathrm{Ca}$ & $23,5 b$ & $5,2 \mathrm{abc}$ & $17,9 \mathrm{bc}$ & $0,7 \mathrm{e}$ & $1,8 b c$ & $4,0 \mathrm{~b}$ \\
\hline$-\mathrm{Mg}$ & $21,1 b c$ & $6,6 \mathrm{ab}$ & $30,4 b$ & $7,8 b$ & $0,7 \mathrm{c}$ & $3,4 \mathrm{~b}$ \\
\hline$-S$ & $18,6 \mathrm{bc}$ & $7,5 \mathrm{ab}$ & $31,6 b$ & $5,8 \mathrm{bc}$ & $3,9 b$ & $1,5 b$ \\
\hline $\mathrm{CV}(\%)$ & 36,3 & 37,2 & 26,4 & 23,4 & 27,9 & 32,2 \\
\hline
\end{tabular}

Rev. Ceres, Viçosa, v. 63, n.5, p. 706-714, set/out, 2016 
ção ao do tratamento completo (Tabela 2); fato esse decorrente da interação antagônica entre esses nutrientes.

Observou-se que as plantas submetidas à omissão de $\mathrm{Mg}$ apresentaram menor teor do nutriente, na parte aérea, de $0,7 \mathrm{~g} \mathrm{~kg}^{-1}$ e, nas raízes de $0,9 \mathrm{~g} \mathrm{~kg}^{-1}$, comparado aos do tratamento completo, na parte aérea, de $4,5 \mathrm{~g} \mathrm{~kg}^{-1} \mathrm{e}$, das raízes, de 7,1 $\mathrm{g} \mathrm{kg}^{-1}$ ) (Tabela 2). O mesmo ocorreu com o $\mathrm{Mg}$ acumulado, sob o tratamento completo, na parte aérea das plantas, de 8,5 e, nas raízes, de 13,2 mg por planta, se comparado aos obtidos, sob os tratamentos deficientes, na parte aérea, de 0,6 e, nas raízes, de 0,7 mg por planta (Tabela 3). Diante dos efeitos da omissão de $\mathrm{Mg}$ no desenvolvimento e no estado nutricional das plantas, observou-se a sintomatologia de deficiência, conforme descrito anteriormente.

Os teores de $\mathrm{S}$ da parte aérea e das raízes variaram de 0,93 a 3,67 e de 3,2 a 7,2 $\mathrm{g} \mathrm{kg}^{-1}$, respectivamente, sob todos os tratamentos, exceto sob o tratamento com omissão de $\mathrm{Mg}$ (Tabela 2). O valor de $1,0 \mathrm{~g} \mathrm{~kg}^{-1}$ foi observado em plantas sob o tratamento com omissão de $S$, no qual não se verificaram sintomas de deficiência nas plantas de milho, por estar abaixo da faixa considerada adequada para a cultura de 1,0 a 2,0 $\mathrm{g} \mathrm{kg}^{-1}$ (Martinez et al., 1999) (Tabela 2).

Verificou-se que, no tratamento com omissão de $S$, os teores desse elemento foram reduzidos significativamente nas raízes, quando comparado com os do tratamento completo (Tabela 2). O mesmo comportamento foi observado por Santi et al. (2006) em sorgo.

Em solução completa, a sequência decrescente de macronutrientes, quanto à parte aérea, foi $\mathrm{K}>\mathrm{N}>\mathrm{Ca}>\mathrm{P}$ $>\mathrm{Mg}>\mathrm{S}$. Nas raízes, na solução completa a sequência de teores diferiu da observada na parte aérea, tendo sido constatado: $\mathrm{K}>\mathrm{N}>\mathrm{Ca}=\mathrm{Mg}>\mathrm{S}>\mathrm{P}$ (Tabela 3). $\mathrm{O} \mathrm{K}$ manteve-se como o nutriente com maior teor na planta, em soluções com omissões de macronutrientes, exceto quando se encontrava omisso na solução.

\section{CONCLUSÕES}

Os sintomas iniciais de deficiência dos macronutrientes N, P, K, Ca, Mg e S ocorreram aos 5, 16, 16, 16 e 22 dias após o transplantio.

O milho apresentou maior produção de matéria seca sob o tratamento completo, em comparação com a dos demais tratamentos.

Os tratamentos com omissão de nutrientes apresentaram sintomas de deficiência na parte aérea.

A produção de matéria seca foi afetada pela omissão de nutrientes, na parte aérea e nas raízes.

A omissão de um nutriente, além de promover diminuição de seu teor na parte aérea da planta de milho, causou desequilíbrio entre os demais nutrientes e, consequente- mente, houve alterações morfológicas, traduzidas como sintomas característicos de deficiência de cada nutriente.

\section{REFERÊNCIAS}

Almeida ML, Sangoi L, Nava IC, Galio J, Trentin OS \& Rampazzo C (2003) Crescimento inicial de milho e sua relação com o rendimento de grãos. Ciência Rural, 33:189-194.

IBGE - Instituto Brasileiro de Geografia e Estatística (2014) Disponível em: <ftp://ftp.ibge.gov.br/Producao_Agricola/ Levantamento_Sistematico_da_Producao_Agricola_[mensal]/ Comentarios/1spa_201403comentarios.pdf>. Acessado em: 16 de abril de 2015.

Bataglia OC, Furlani AMC, Teixeira JPF, Furlani PR \& Gallo JR (1983) Métodos de análise química de plantas. Campinas, Instituto Agronômico. 48p. (Boletim Técnico, 78).

Cantarella H \& Duarte AP (2004) Manejo da fertilidade do solo para a cultura do milho. In: Galvão JCC \& Miranda GV (Eds.) Tecnologia de produção de milho. Viçosa, UFV. p.139-182.

Carelli MLC, Ungaro MRG, Fahl I \& Novo MCSS (1996) Níveis de nitrogênio, metabolismo, crescimento e produção de girassol. Revista Brasileira de Fisiologia Vegetal, 8:123-130.

Coelho AM, Waquil JM, Karan D, Casela CR \& Ribas PM (2002) Seja o doutor do seu sorgo. Piracicaba, Potafos. 24 p. (Arquivo do Agrônomo, 14).

Cooper HD \& Clarkson DT (1989) Cycling of amino-nitrogen and other nutrients between shoots and roots in cereals - A possible mechanism integrating shoot and root in the regulation of nutrient uptake. Journal Experimental Botany, 40:753-762.

Ericson T (1995) Growth and shoot: root ratio of seedlings in relation to nutrient availability. Plant and Soil, 168/169:205214 .

Fonseca IM, Prado RM, Alves AU \& Gondim ARO (2008) Crescimento e nutrição do sorgo (cv. BRS 304) em solução nutritiva. Revista de Biologia e Ciências da Terra, 8:113-124.

Gill MA, Salim M \& Zia MS (1992) Maize growth and uptake of phosphate and copper at different ambient phosphate concentrations. Soil Science Plant Nutrition, 38:631-636.

Gondim ARO, Prado RM, Alves AU \& Fonseca IM (2010) Eficiência nutricional do milho cv. BRS 1030 submetido à omissão de macronutrientes em solução nutritiva. Revista Ceres, 57:539544 .

Hernandez RJM \& Silveira RI (1998) Efeitos da saturação por bases, relações $\mathrm{Ca}: \mathrm{Mg}$ no solo e níveis de fósforo sobre a produção de material seco e nutrição mineral do milho (Zea mays L.). Scientia Agrícola, 55:79-85.

Hoagland DR \& Arnon DI (1950) The water culture method for growing plants without soils. Berkeley, California Agricultural Experimental Station. 347p.

Lima A, Mischan MM \& Neptune AML (1981) Efeito isolado e combinado de nitrogênio, fósforo e potássio no desenvolvimento do girassol. Anais da ESALQ, 43:857-873.

Lima HN (1994) Crescimento inicial a campo de sete espécies arbóreas nativas em resposta a adubação com NPK. Dissertação de Mestrado. Escola Superior de Agricultura de Lavras, Lavras. $67 \mathrm{p}$.

Malavolta E \& Violante Netto A (1989) Nutrição mineral, calagem, gessagem e adubação dos citros. Piracicaba, Potafos. 153p.

Malavolta E (1980) Elementos de nutrição mineral de plantas. São Paulo, Agronômica Ceres. 251p. 
Malavolta E, Vitti GC \& Oliveira SA (1997) Avaliação do estado nutricional das plantas: princípios e aplicações. $2^{\mathrm{a}}$ ed. Piracicaba, Potafos. 319p.

Marschner H (1995) Mineral nutrition of higher plants. London, Academic. 889 p.

Martinez HEP, Carvalho JG \& Souza RB (1999) Diagnose foliar. In: Ribeiro AC, Guimarães PTG \& Alvarez VVH (Eds.) Recomendações para uso de corretivos e fertilizantes em Minas Gerais: 5 $5^{a}$ Aproximação. Viçosa, Comissão de Fertilidade do solo do Estado de Minas Gerais. p.143-168.

Mengel K \& Kirkby E (1987) A. Principles of plant nutrition. Bern, International Potash Institute. 687p.
Prado RM (2008) Nutrição de plantas. São Paulo, Editora UNESP. $407 \mathrm{p}$.

SAEG: Sistema para Análises Estatísticas e Genéticas (2007) Versão 9.1. Viçosa, Fundação Arthur Bernardes/UFV. CD-ROM.

Santi A, Camargos SL, Scaramuzza WLMP \& Scaramuzza JF (2006) Deficiências de macronutrientes em sorgo. Ciência Agrotécnica, 30:228-233.

Viégas IJM, Batista MMF, Frazão DAC, Carvalho JG \& Silva JF (2002) Avaliação dos teores de N, P, K, Ca, Mg e S em plantas de gravioleira cultivadas em solução nutritiva com omissão de macronutrientes. Revista Ciências Agrárias, 38:17-28. 